University of Wollongong

Research Online

Faculty of Social Sciences - Papers (Archive) Faculty of Arts, Social Sciences \& Humanities

2016

Young people in the global north: Environmental heroes or pleasure-seeking consumers

Elyse R. Stanes

University of Wollongong, estanes@uow.edu.au

Natascha Klocker

University of Wollongong, natascha@uow.edu.au

Follow this and additional works at: https://ro.uow.edu.au/sspapers

Part of the Education Commons, and the Social and Behavioral Sciences Commons

Research Online is the open access institutional repository for the University of Wollongong. For further information contact the UOW Library: research-pubs@uow.edu.au 


\title{
Young people in the global north: Environmental heroes or pleasure-seeking consumers
}

\begin{abstract}
Young people in the Global North have disparate identities in relation to environmental sustainability; they are purportedly more knowledgeable and concerned about the environment and climate change than older generations, but are also typecast as leaders of a hedonistic consumer culture. This chapter undertakes a critical review of the key research trajectories across geography, youth studies, and the social sciences that pertain to young people, consumption, and environmentalism. It draws on recent research that has sought to complicate the positioning of contemporary young people as either "hedonistic consumers" or "environmental heroes." The reality, for many young people, lies in between these two visions. This chapter foregrounds recent research that eschews a one-size-fits-all approach to young people, consumption, and environmentalism, by highlighting their unique everyday sustainabilities.
\end{abstract}

\section{Keywords}

heroes, north, pleasure, environmental, global, consumers, people, seeking, young

\section{Disciplines}

Education | Social and Behavioral Sciences

\section{Publication Details}

Stanes, E. \& Klocker, N. (2016). Young people in the global north: Environmental heroes or pleasureseeking consumers. In N. Ansell, N. Klocker \& T. Skelton (Eds.), Geographies of Global Issues: Change and Threat (pp. 553-574). Singapore: Springer. 
Stanes, E. and Klocker, N. (2016) 'Environmental Heroes and Pleasure-seeking Consumers: Conflicting Narratives of Youth and Young People', in Ansell, N., Klocker, N. and Skelton, T. (Eds) (2016) Geographies of Global Issues: Change and Threat, Vol. 8 of Skelton, T. (ed) Geographies of Children and Young People, Springer, Singapore.

http://www.springer.com/us/book/9789814585538

Elyse Stanes, estanes@uow.edu.au, School of Geography and Sustainable

Communities, Australian Centre for Cultural Environmental Research, University of Wollongong, New South Wales, Australia

Dr. Natascha Klocker, natascha_klocker@uow.edu.au, School of Geography and Sustainable Communities, Australian Centre for Cultural Environmental Research, University of Wollongong, New South Wales, Australia 


\begin{abstract}
Young people in the Global North have disparate identities in relation to environmental sustainability; they are purportedly more knowledgeable and concerned about the environment and climate change than older generations, but are also typecast as leaders of a hedonistic consumer culture. This chapter undertakes a critical review of the key research trajectories across geography, youth studies and the social sciences that pertain to young people, consumption and environmentalism. It draws on recent research that has sought to complicate the positioning of contemporary young people as either 'hedonistic consumers' or 'environmental heroes'. The reality, for many young people, lies in between these two visions. This chapter foregrounds recent research that eschews a one-size-fits-all approach to young people, consumption and environmentalism, by highlighting their unique everyday sustainabilities.
\end{abstract}

Keywords: Youth, young people, young consumers, consumption, environmental sustainability, Global North, environmental attitudes, environmental behavior, everyday sustainabilities 


\section{Introduction}

Recent research on young people, the environment and sustainability in the Global North has often been framed around two paradoxical assertions. The first assertion is that contemporary young people are thoughtless and wasteful consumers. Media discourses and popular culture have depicted contemporary young people - specifically Generation Y - as self-serving, conceited, lazy, wasteful and hedonistic (Hoey, 2008; Hume, 2010). They live in an era characterized by an ever-expanding range of consumer products, such as clothing and electronics. Said to be caught up in rapid trend cycles and fast fashion, these young people have been accused of extravagance and throw-away consumerism (Han, 2015; Hoey, 2008; Griffin et al., 2005), with attendant environmental implications.

The second, and seemingly paradoxical, assertion is that young people in the Global North are important 'agents of change’ (Bentley et al., 2004:1), ‘Trojan horses’ for more environmentally sustainable lifestyles (Collins and Hitchings, 2012:195). Over the past decade, the same generation that has been accused of unbridled consumerism has been lauded for its environmental consciousness and capacity to instigate environmental change at a range of geographical scales (Autio and Heinonen, 2004; Autio et al., 2009; Bentley et al., 2004; Fielding and Head, 2012; Percy-Smith and Burns, 2013). Young people have been shown to play an important role as bearers of environmental knowledge in diverse spaces; the home, the school and within and across communities (Autio et al., 2009; Ballantyne et al., 2001; Breunig et al., 2013; Collins, 2014. 2015; Hadfield-Hill, 2013; Horton et al., 2013; Larsson et al., 2010; Percy-Smith and Burns, 2013). 
Existing research in the Global North has typically been framed around one of the above narratives; portraying contemporary young people as agents of environmental benefit (Bentley et al., 2004) or harm (Hume, 2010). In this process, young people have been positioned as a uniform mass, and their complex, multiple and shifting identities and priorities have been stifled, misinterpreted or distorted (Collins and Hitchings, 2012; Hopkins, 2013). While much of the critique around young people's consumption practices has focused specifically on Generation Y (also known as the Millennials, born between 1980 and 1994), the literature that is drawn upon in this chapter foregrounds the attitudes, behaviors and practices of a broader group of young people, aged from 12 to 34 years at the time of writing. This age bracket reflects the age boundaries adopted in the literature on ‘young people’ upon which this chapter has drawn.

Rather than defining ‘youth’ as an indiscriminate boundary that sits between life stages, Hopkins and Pain (2007) have urged geographers to look towards a relational geography of age focused on fluidity and transition. In other words, recognizing the meaning and experience of age and aging intersects with cultural, social, environmental, political and historical processes (Hopkins and Pain, 2007). Throughout this chapter the terms ‘youth’ and ‘young people' are used interchangeably to refer to a period of adolescence or reaching of physical maturity that coincides with the accumulation of responsibilities, behaviors and life skills, and also encompasses the stage of young adulthood (Collins and Hitchings, 2012; Gram-Hanssen, 2007; Hopkins, 2013; Valentine, 2000, 2003). Research on young children is not a focus of this review, though it is recognized that the boundaries between 'youth' and ‘children’ are not fixed and the two are inextricably entangled (Evans, 2008). This chapter also draws on research that situates young people within particular generational cohorts such as Generation Y and the subsequent Generation Z (born between 1995 and the present) (Han, 
2015). Generational cohorts have been deemed an important social category across geography and more broadly in the social sciences. Individuals born within the same time period tend to share a range of experiences ‘in their maturation and socialization’ (Büttner and Grübler, 1995: 116). Each generational label comes with its accompanying clichés and stereotypes and generational cohorts are often the target of critique and praise, particularly surrounding ideas of hedonistic consumption or pro-environmental sustainability (Büttner and Grübler, 1995; Hersch and Viscusi, 2006; Hume, 2010; Stanes et al., 2015). 'Generation’ is also applied throughout this chapter to describe relationships within families, home and communities, for instance, between parent and child. While generational differences in environmentalism are a primary concern of this chapter - whether within families or in reference to broader generational cohorts - it was not possible to consistently adopt the term generation in this chapter. Instead, the terms 'youth', 'young people' and references to Generation Y are used interchangeably, in order to be faithful to the terminology used in the original studies that have been drawn upon.

This chapter undertakes a critical review of the key research trajectories in young people’s geographies, youth studies and the social sciences more broadly, pertaining to youth, consumption, sustainability and environmentalism in the Global North. The geographical scope of the literature reviewed is confined to the Global North, including the UK, Finland, Sweden, Australia, the USA and Canada. The focus of the chapter is timely because of urgent concerns about the climate change impacts of high-consumption lifestyles in the Global North (Gibson et al., 2013). While geographers and social scientists have begun to tease apart everyday sustainabilities in this context, particularly at the scale of the household, young people are rarely the focus of such reviews (for exceptions see Ballantyne et al., 2001; Collins, 2014, 2015; Gram-Hanssen, 2007; Klocker et al., 2012; Larson et al., 2010; Stanes et 
al., 2015). This chapter highlights recent geographical research that has sought to fill this gap and aims to open up conversations for progressing this research agenda. The chapter begins by explicating the importance of 'youth' in examinations of environmental sustainability. It then goes on to outline the ways that young people have been positioned and envisioned as 'agents of change', capable of resolving environmental and sustainability dilemmas in the present and into the future. The second half of the chapter focuses more specifically on youth consumption research, and the 'hedonistic consumer' tag. The closing sections of the chapter complicate binary constructions of contemporary young people, by foregrounding their unique and already existing everyday sustainabilities.

\section{Environmental sustainability: the importance of a youth-focus}

Two strands of thinking highlight the importance of young people to conversations about environmental sustainability. First, a significant body of evidence from geography (Hopkins, 2013; Horton et al. 2013; Valentine, 2000, 2003), environmental education (Ballantyne et al. 2001) and sociology (Larsson et al., 2010) has demonstrated that youth is a key period of transition and socialization during which norms, practices, habits and values (including those pertaining to environmental, political and social issues) are established. Geographers have made an important contribution to these debates by highlighting the spatial nature of environmental concern and the importance of home, school and community to enacting environmental practices (Collins, 2014, 2015; Collins and Hitchings, 2012; Hadfield-Hill, 2013; Horton et al., 2013; Percy-Smith, 2013; Percy-Smith and Burns, 2010). Recent geographical literature has also begun to underline what is distinctively different about contemporary youth, particularly when compared to older generations (Stanes et al., 2015). As young people transition from their teens into adulthood they become independent of their parents and choose a particular way of life. The habits that young people develop in their 
youth will have a decisive impact on future consumption patterns and lifestyles (Heiss and Marras, 2009). The behaviors formed within this stage of 'transition' can become settled into particular 'material, social and spatial organizational settings' which can prove difficult (and costly) to change later in life (Büttner and Grübler, 1995: 119). Lifestyles associated with particular environmental outcomes (whether harmful or beneficial) can become habituated during this important life stage.

Second, when young people have featured in policy discourses around environmental sustainability, their role has often been framed in the future tense. Policies and government programs are often geared towards equipping children and young people for the roles they can/should play in the future as adults, rather than the important impact that they have as ‘authentic participants’ in leadership in the present day (Malone, 2001: 8; see also Evans and Honeyford, 2012; Hayward, 2012; Fielding and Head, 2012; Horton et al., 2013; Percy-Smith and Burns, 2013). As Evans and Honeyford (2012:68) highlighted throughout their critical review of the UK Labour Government’s Brighter futures, greener lives: sustainable development action plan 2008-2010, the framing of young people within pre-emptive policy has been one of 'dual positioning' where the concern for the child in the present is often secondary to concerns about future adulthood (see also Malone, 2001). Present generations of young people have also been branded as the future victims of previous generations' lack of environmental action; as passive actors 'to be feared for' (Horton et al., 2013:250 original emphasis). The positioning of young people as 'future adults' who will one day bear responsibility for tackling environmental issues acts to diminish their important contributions as political and environmental actors and as co-constructors of community here and now (Evans and Honeyford, 2012; Hayward, 2012; Horton et al., 2013). Researchers in the field of children's and young people's geographies have been at the forefront of efforts to 
dismantle this futuristic focus, foregrounding children and young people's environmental roles in the present day (Collins, 2014; Evans and Honeyford, 2012; Jenkins and Pell, 2006). These criticisms match broader concerns which have been voiced within children's geographies and allied disciplines over several decades. Children and young people have too often been positioned as adults in waiting, rather than competent and important actors in the present (James and James, 2004). Since it is evident that 'the quality of the environment children grow up in determines the quality of their lives'(Malone, 2001:7), improving children and young people's wellbeing in the present should be at the root of policy on environmental or sustainable development rather than placing emphasis solely on the future (Evans and Honeyford, 2012).

The importance of young people's involvement in environmental sustainability agendas has been acknowledged in a range of international instruments including: Agenda 21 (United Nations Environmental Programme, UNEP), Chapter 25 of the United Nations Conference on Environment and Development (UNCED); YouthXChange (UNEP/UNESCO), and also through a range of NGOs and environmental networks such as YOUNGO, Young Friends of the Earth, Global Action Plan International, the World Wildlife Fund and The Otesha Project. The establishment of Agenda 21 was an outcome of the 1992 United Nations Conference on Environment and Development held in Rio de Janeiro. The primary aims of Agenda 21 were to implement a wide-ranging action plan for global sustainability and to better communicate the need for global economic development without compromising the ability of future generations to meet their own needs (Malone, 2001; UNEP, no date). The inclusion of children and young people in Chapter 25 of Agenda 21 was a turning point in global policy and environmental initiatives. Chapter 25 of Agenda 21 emphasized that: 
It is imperative that youth from all parts of the world participate actively in all relevant levels of decision-making processes because it [environmental protection and economic and social development] affects their lives today and has implications for their futures. In addition to their intellectual contribution and their ability to mobilize support, they bring unique perspectives that need to be taken into account (United Nations Conference on Environment and Development 1992, 25.2).

Initiatives like Agenda 21 have provided a framework for youth-focused environmental policy development across geographical scales, from the global to the local. The significance of young people's engagement in environmental sustainability agendas was more recently articulated by the United Nations Education Program and United Nations Educational, Scientific and Cultural Organization (UNEP/UNESCO). In 2000 UNEP/UNESCO developed and endorsed the YouthXchange program to bring youth to the forefront of environmental discussions in the present day:

They [young people] possess aspirations particular to this time in their lives...The involvement of young people should not be relegated to some ambiguous future; rather their participation is needed now. The notion that young people will one day 'inherit' the earth should be dispelled; in fact, their involvement today is cogent for shaping this world. Young people have a legitimate demand to be heard, to express themselves; moreover, it is imperative that their valuable contribution to society be recognized (UNEP/UNESCO, 2006 in Heiss and Marras, 2009:183).

But translating these laudable objectives into action has been a challenge. Percy-Smith and Burns (2013:324) have lamented that broad policy initiatives often lead to 'naïve, simplistic 
and tokenistic' approaches that allow young people to 'have a say' in relation to environmental issues, without supporting their active participation (see also Percy-Smith, 2010). Notwithstanding these challenges, a growing body of geographical research has highlighted the important roles that young people are playing as agents of environmental change - oftentimes in everyday contexts of home, school and in the wider community (Ballantyne et al., 2001; Breunig et al., 2013; Collins, 2014, 2015; Hadfield-Hill, 2013; Horton et al., 2013; Percy-Smith and Burns, 2013; Vivoni, 2013). Young people’s mundane everyday practices have important environmental, ecological and political consequences (Horton et al., 2013). The following sections detail two distinct bodies of literature that have taken the present day environmental implications of contemporary young people’s everyday lives seriously - for better (as environmental change agents) or for worse (as hedonistic and wasteful consumers).

\section{Young people in the Global North: agents of (everyday) environmental change?}

The label 'citizen-consumer' (Collins and Hitchings, 2012) has been attached to contemporary young people, who have been lauded for their environmental consciousness and positioned as important environmental change agents (Autio and Heinonen, 2004; Autio

et al., 2009; Bentley et al., 2004; Fielding and Head, 2012; Percy-Smith and Burns, 2013). Government and grassroots organizations have urged young people to carry out everyday sustainabilities in the home, the school and across their local and global communities. But research has also found that young people struggle to translate environmental concern into action (Fielding and Head, 2012). This section provides a review of key debates across geography and the social sciences that highlight the high levels of environmental concern and knowledge in this generation of young people. This is followed with a review of recent 
research that highlights some of the difficulties that contemporary young people face when attempting to transform environmental concern into environmental action.

\section{Young people: environmentally aware, concerned and knowledgeable}

Over the past decade, numerous studies have applauded contemporary young people in the Global North for their environmental awareness. Such studies have typically been framed around quantitative, survey-based analyses of young people’s environmental concern (Bentley et al., 2004; Jenkins and Pell, 2006); climate change awareness (Carbon Trust, 2012; Forum for the Future, 2008; Ojala, 2012); and 'green' behaviors and practices (Autio and Heinonen, 2004; Autio et al., 2009). Research has consistently shown that young people are environmentally aware and concerned citizens (Bentley et al., 2004; Carbon Trust, 2012; Forum For the Future, 2008; Jenkins and Pell, 2006; Ojala, 2007), particularly when compared to older generations (Hersch and Viscusi, 2006; Stanes et al., 2015). For instance, in a survey of 224 young people aged between 12 and 28 from rural, regional and metropolitan Australia, nine out of ten reported being concerned or very concerned about the environment (Bentley et al., 2004). Also in Australia, Fielding and Head's (2012) online survey of 4540 youths aged between the ages of 12 and 24 revealed that young people held high levels of environmental concern and knowledge, and a greater belief in individual and community responsibility for environmental protection. Jenkins and Pell (2006) conducted a survey with 1277 youth aged 13 to 17 years from 34 secondary schools across England. In that sample, 76 per cent of young people disagreed or strongly disagreed with the statement that threats to the environment were not their business. Most of the young people surveyed (58.5\%) also disagreed with the statement that environmental problems have been exaggerated. 
Research has also found that contemporary young people are concerned about the effects of climate change. The Future Leaders survey was conducted with 23,596 students studying at universities across the UK in 2008 (Forum for the Future, 2008). It found that 85 per cent of university students were concerned that climate change would affect their lives in 2032 (Forum for the Future 2008). The Carbon Trust Survey (2012) was carried out across six countries (USA, UK, China, South Korea, Brazil and South Africa) and involved 2800 young people aged between 18 and 25 years. Results for the UK and USA (each with a sample size of 501) revealed that the majority of young people were apprehensive about the impacts of climate change (Carbon Trust Survey, 2012). Furthermore, 63 per cent of young people from the USA and 64 per cent of those from UK thought that their generation was more concerned about climate change than their grandparents’ generation (Carbon Trust Survey, 2012). This observation has been confirmed in generational studies which consistently reveal higher levels of environmental concern and awareness amongst younger generations. For instance, in an Australian case study involving 1,328 households from different generational cohorts, geographers Stanes et al. (2015) found that young people expressed pro-environmental attitudes at a higher frequency than older generations. More specifically, Generation Y (aged between 18 and 34) were more likely than older generations, like the 'Baby Boomers' (aged between 45 and 64) or the 'Silent Generation' (aged 65 years or older), to express general environmental concern. Generation Y respondents were more inclined to take a proenvironmental lean towards statements like 'if things were to continue on their current course, we will soon experience a major environmental disaster' (77.8\% agreed with this statement versus $62.9 \%$ of Silent Generation), or 'it would embarrass me if my friends thought my lifestyle was purposefully environmentally friendly' (95.6\% disagreed with this statement compared with $82.1 \%$ of Silent Generation). The survey indicated that young respondents also expressed higher rates of climate change belief and concern than older 
generations and were significantly more concerned about environmental futures than older generations (Stanes et al., 2015). Generation-specific environmental differences were also apparent in Hersch and Viscusi’s (2006) analysis of the 1999 Eurobarometer 51.1 survey. The analysis of over 14,000 responses across 15 European countries (including France, Great Britain, Ireland, the Netherlands and Spain) revealed that a higher proportion of younger age groups (between 15- 24 and 25-34) believed that they were more informed about major environmental problems (including climate change) than older generational groups (respondents between 55 and 64 and 65+) (Hersch and Viscusi, 2006). Survey results also found that younger generations were more worried about global warming than older generations (Hersch and Viscusi, 2006).

\section{Young people: practising everyday sustainabilities?}

Evidence of contemporary young people’s environmental concern and knowledge has generated a sense of optimism that they can play a role as 'active agents of change' in response to pressing environmental and social problems (Bentley et al., 2004; Hadfield-Hill, 2013; Ojala, 2012). Accordingly, they have been identified as a ‘critical target group’ for environmental sustainability programs that seek to harness their environmental concerns and to turn these into action. This section focuses on tangible examples of young people's everyday sustainabilities in their communities, schools and homes.

In the UK, the YouthXchange program has brought attention to the importance of young people’s present day roles within households, regions and communities. Structured as a 'toolkit', YouthXchange aims to encourage young people to reflect on tangible, everyday aspects of sustainable living, from making choices about the types of clothing they buy, to thinking about the environmental implications of their transport and tourism decisions (Heiss 
and Marras, 2009). The use of case studies in creating positive narratives of sustainable consumption has been hailed as a helpful instrument to motivate young people to reflect on their consumption patterns (Heiss and Marras, 2009). The YouthXchange program has been implemented across approximately twenty partner organisations, from NGOs to local governments across the Global North and South. The Norwegian government, for instance, has implemented YouthXchange toolkits in all secondary schools and teaching libraries. Across a range of countries, federal and state government programs, local council initiatives and schools curricula have implemented other educational efforts to encourage sustainable behaviors among young people in their everyday lives. Breunig et al.'s (2013) study of 33 secondary students from two schools in Ontario, Canada suggested that Environmental Studies Programs (ESPs) have long-lasting effects on a student's belief that they can influence environmental change. Students reported increased environmental knowledge that led to meaningful behavior change including reduced water usage, participation in recycling and energy saving measures (Breunig et al., 2013). An increased sense of self-efficacy also armed students with the confidence to share environmental information with others - at home and with their peers. Often, the aim of these initiatives is to encourage young people to 'tread lightly’ on the planet, by targeting everyday consumption behaviors (Collins, 2014: 18; Percy-Smith and Burns, 2013). Whether run by NGOs, local government or schools these initiatives have an important role to play in grounding sustainability dilemmas in students' 'real world' experiences and daily lives (Breunig et al., 2013).

Such programs have also recognized the important role that young people can play as environmental change agents in the home. Young people are already active members of households, extended families, friendship networks and communities (Collins 2015; Hadfield-Hill, 2013; Larsson et al., 2010). They have the capacity to 'transmit' environmental 
knowledge and sustainable behavior change across and between such networks (Ballantyne et al., 2001; Bentley et al., 2004; Collins, 2014, 2015; Griffin et al., 2005; Larsson et al., 2010). Particular attention has been paid to their roles in promoting sustainability within families/households, and also within peer groups. In the household, geographical research has focused on the flow of information from child to parent (or another close member of family) through what is commonly known as 'pester power’ (Hadfield-Hill, 2013; Larsson et al., 2010). In Australia, Ballantyne et al. (2001) found that young people brought environmental learning from school into the home by prompting other household members to turn off the lights, or to turn off the tap when brushing teeth and washing the dishes. In that study, almost one-third of young people aged between nine and eighteen years acknowledged that measures learned at school could be implemented at home and within the wider community (Ballantyne et al., 2001). Young students have great potential to act as a source of 'intergenerational influence' and as 'catalyst[s] of environmental change' in the domestic sphere (Ballantyne et al., 2001: 9). When given the appropriate tools and knowledge young people 'are in the ideal position to extend the environmental agenda beyond the confines of the classroom, to homes and the wider community’ (Hadfield-Hill, 2013: 356). However, a number of geographers have emphasized that this is not a unidirectional process. Sustainable behavior change in the home is complex and involves negotiations across generations (Collins, 2015; Hadfield-Hill 2013; Klocker et al., 2012). Environmental knowledge and sustainable practices flow bidirectionally between household members: parents, children, siblings and (when present) grandparents (Ballantyne et al., 2001; Hadfield-Hill, 2013; Percy-Smith and Burns, 2013). Green practices within the home depend upon intra-family effort and flows of encouragement. For instance, Klocker et al.’s (2012) study of Australian extended family households found that younger household members considered themselves more committed to environmental causes than their co-resident parents and/or grandparents (see also Breunig 
et al., 2013). Older generations - while more reluctant to espouse openly 'green’ values and, in some instances, expressing climate change skepticism - held innately sustainable values like thrift and frugality, and attempted to pass these on to their children (Klocker et al., 2012).

The aforementioned studies serve as a reminder that everyday spaces of consumption and sustainability - such as the home - are multifaceted and are 'characterized by reflectivity and change’ (Collins and Hitchings, 2012: 195; Stanes et al., 2015). Individuals, families and communities respond to environmental information and enact more or less sustainable practices differently. Crucially, contemporary young people are not (nor should they be) ‘enablers in isolation’ (Hadfield-Hill, 2013:356). While it is important to acknowledge the unique environmental capacities of young people, different generations bring diverse environmental skills to the table. The caricature of young people as environmental 'heroes' is limited and limiting; it neglects the nuances of everyday life and relationships with family members, peers and the wider community.

\section{The challenges of translating environmental concern into environmental action}

Environmental programs and educational initiatives targeted at contemporary young people aim to capitalize upon evidence of their environmental concern and awareness by translating pro-environmental attitudes into green behaviors with meaningful and lasting impacts (Ballantyne et al., 2001; Bentley et al., 2004; Collins, 2014; Percy-Smith and Burns, 2013). In so doing, they often aim to equip young people ‘with a "can do” attitude’ (Collins, 2014:19), and to foster a sense of empowerment and self-efficacy by providing young people with the necessary knowledge and skills to respond to pressing socio-ecological problems (Collins, 2014; Hadfield-Hill, 2013; Jenkins and Pell, 2006; Percy-Smith and Burns, 2013). Youth involvement in sustainability initiatives and educational programs has been associated 
with feelings of satisfaction and self-worth (Ojala, 2012). These feelings have, in turn, been identified as positive predictors of future sustainable behaviors (Ojala, 2007, 2012). Such positive outcomes suggest that there are worthwhile benefits in engaging young people in sustainability initiatives (Collins, 2014; Ojala, 2012; Percy-Smith and Burns, 2013).

Despite optimistic signals about young people’s levels of environmental concern, environmental consciousness only indicates a general disposition to environmentally friendly action. Further, a number of studies have raised concerns that contemporary young people may be struggling to cope with the prospect of dramatic environmental change in the future. The images that young people have of futures under increased environmental pressure can be negative, fragmented and bleak (Ojala, 2007). Research has found a strong association between future scenarios and negative emotions such as worry, sadness, anger and pessimism amongst young people (Ojala, 2007). Adverse emotions are thought to hinder the translation of environmental intentions into more sustainable action (Fielding and Head, 2012; Ojala, 2012). The risk is that young people may become disengaged from issues that pertain to the environment and climate change over both the short and longer-term. Young people may be deeply concerned about environmental problems, but experience feelings of anger, frustration or pessimism because outcomes of sustainable action are not immediately visible or apparent (Bentley et al., 2004; Fielding and Head, 2012; Jenkins and Pell, 2006; Ojala, 2012). Despite the efforts and programs outlined above, some young people have also become disengaged from environmental issues through what has been called the 'bystander effect' (Fielding and Head, 2012: 172; Ojala, 2007). That is, young people may feel a reduced sense of motivation amidst uncertainty about how they are able to meaningfully contribute to the resolution of complex environmental problems. For instance, in Jenkin and Pell’s (2006) study of 1277 English secondary school youths aged 13 to 17 years, 70 per cent agreed that 'each of us can 
make a substantial contribution to environmental protection'. However, the young people surveyed were less optimistic about what they could do themselves - only 44 per cent agreed that they could personally influence what happens to the environment (Jenkins and Pell, 2006). In a survey conducted with 501 young adults from the US aged between 18 and 25, 30 per cent indicated that they were trying to reduce their carbon footprint, but still thought they could do more (Carbon Trust Survey, 2012). Another 23 per cent of young people wanted to reduce their carbon footprint but were confused about how to do so (Carbon Trust Survey, 2012).

As Fielding and Head (2012) found, high levels of environmental consciousness do not necessarily lead to pro-environmental behaviors. Barriers that inhibit the transmission of proenvironmental values to environmentally sustainable behaviors have been widely referred to over the past decade as the ‘value-action gap' (Blake, 1999; Kollmuss and Agyman, 2002). In their Australian sample with 4,540 young people aged between 12 and 24, Fielding and Head (2012) found that there were a range of reasons why young people did things that they knew would harm the environment. The financial cost of adopting sustainable behaviors was a highly cited reason for 47.8 per cent of 18 to 24 year olds. Another 37.6 per cent of young people aged between 12 and 17, and 42.2 per cent of those aged between 18 and 24, said they were too lazy to engage in environmentally positive behaviors (Fielding and Head, 2012). Furthermore, 37 per cent of 12 to 17 year olds, and 51.5 per cent of 18 to 24 year old youths, indicated that they sometimes did things that are bad for the environment because they felt that they had no other choice (Fielding and Head, 2012). In light of this, Percy-Smith and Burns (2013) have argued that more innovative forms of learning are required to offer young people a more active and central role as change-makers. In their study with 26 secondary school students in the UK, Percy-Smith and Burns (2013) found that young people became 
more enthusiastic and motivated about their role as ‘agents of change’ when they formed and initiated environmental projects themselves, without adult-imposed restrictions. An example of this was a group of students who developed a Sustainable Food Guide for their local community. Raising awareness of local products had a direct effect on the local food economy and retail through a change in shopper demand, and thus improved the young people’s sense of efficacy (Percy-Smith and Burns, 2013).

Clearly, the path from 'green' attitudes to 'green’ behaviors is far from straightforward. This is particularly evident in the disjuncture between representations of contemporary young people as environmentally concerned and engaged citizens, and alternative framings of wasteful and thoughtless consumption. At the same time, some have argued that the valueaction gap may appear to be particularly pronounced for this generation of young people, as measurements of pro-environmental attitudes and behaviors remained focused on 'traditional' ideas of what it means to be 'green’ (Stanes et al., 2015). Research that attends to the unique qualities and activities of contemporary youth is required to provide a fuller picture of how, why and if young people find it hard to transform environmental concern into action. The next section of this chapter reviews literature pertaining to contemporary young people’s purportedly unsustainable and resource-intensive consumption behaviors; including recent efforts by geographers to complicate the caricature of the hedonistic young consumer.

\section{Young people and material and resource consumption}

People living and working in the Global North consume an inequitable proportion of the world's resources. Young people are no exception. While scholarly interest in contemporary young people’s consumption patterns has been pronounced in recent years (Autio, 2005; Collins, 2014; Collins and Hitchings, 2012; Gram-Hanssen, 2007; Gibson and Stanes, 2011; 
Griffin et al., 2005; Valentine, 2000), it is not new. In 1959, Mark Abrams wrote The Teenage Consumer. This widely cited benchmark study investigated the role of consumption in the lives of young people as a 'newly franchised' group experiencing greater independence from their parents or guardians and who are afforded the right to exercise greater powers of individuality and freedom. Abrams (1959) noted that young people were not only financially independent from their elders, but that their disposable income afforded them with opportunities to consume according to the latest fashions and trends - and most importantly, to be seen to be doing so by their peers (Collins, 2014). Young people’s consumption of fashionable products has been well documented and critiqued over the ensuing decades including by human geographers (see Collins, 2014, 2015; Collins and Hitchings, 2012; Gibson and Stanes, 2011; Hopkins, 2013). The spending power and consumption patterns of contemporary young people in the Global North have been singled out as particularly problematic. Generation Y, in particular, has been lambasted for being at the forefront of a 'consumer behemoth, riding atop a new youth economy of astounding scale and extravagance’ (Howe and Strauss 2000: 265; see also Hume, 2010).

As with previous generations, the consumption patterns of the current cohort of young people are influenced by family norms, peer group expectations and a desire for self-expression. Youth identities are fluid and multiple and young people often juggle various identities to ascertain who they are and want to be (Hopkins, 2013). Youth as a period of transition is often a time of great uncertainty, where consumption of material goods can serve as source of (or scaffold for) self-identity and as an outlet for self-expression (Collins, 2014; Griffin et al., 2005; Heiss and Marras, 2009; Hopkins, 2013). Through their consumption patterns, young people strive to gain independence from their elders, to express themselves and to experiment with diverse identities (Griffin et al. 2005). Products that are consumed socially, such as 
clothes, electronics or music are vital here, as the visibility of these products signals status to others or indicates participation in particular trends or subcultural groups (Autio and Heinonen, 2004; Bentley et al., 2004). Conspicuous consumption - that is, consumption which is intended to achieve status through the obvious display of fashionable items (Veblen, 2007[1899]) - is an important facet of young people's engagements with their peer group (Collins, 2014). Acts of conspicuous consumption are central to the development of many young people's relationships, and the constant tussle of 'standing out' enough to be perceived as an individual, while still ‘fitting in’ with peers (Autio et al., 2009; Bentley et al., 2004; Collins and Hitchings, 2012; Griffin et al., 2005; Wilska, 2003).

While previous generations of young people also practised conspicuous consumption, the overarching sway of contemporary consumer culture in the Global North has arguably paved the way for a further materialization of youth culture (Collins, 2014). The desire to keep pace with the latest trends and fads (Griffin et al., 2005) is difficult to resist in the present era of relatively cheap and constantly updated consumer products, such as clothing and electronics (mobile phones, mp3 players, tablets and laptops), also known as ‘fast fashion’. Countless and constantly updated products aimed squarely at young people have fostered and enabled a cultural landscape of youth consumption (Wilska, 2003). In this context, young people’s relationships with 'things' are often fleeting and the satisfaction gained through acquisition short lived (Griffin et al., 2005). Short-term happiness and fulfilment experienced through the act of consumption regularly entails spending on items that give immediate pleasure, such as clothes or make-up, rather than investment in meaningful and long-lasting belongings (Autio and Heinonen, 2004). Youth subcultures create pressure to purchase new items - thus as participation in subcultures and groups increases, so too does the total volume of possessions acquired during the teenage years (Collins, 2014). Previously valued items are readily 
abandoned to make way for new consumer items 'once a subgroup or trend has been deemed the wrong choice' (Collins, 2014: 39). Also present within cultures of youth consumption are growing social anxieties and the peer pressure to buy 'stuff' in order to fit in or keep up with ever changing trends (Bentley et al., 2004; Griffin et al., 2005). Numerous studies have shown that the cost of being different, of not belonging or not being in step with consumer 'trends', is a substantial source of anxiety for young people (Griffin et al., 2005; Heiss and Marras, 2009). What might be labelled wasteful or hedonistic consumption is, in the everyday lives of young consumers, actually a complex negotiation of identity, individuality, belonging and self-esteem. Either way, the levels of resource consumption enabled by affordable fast fashion and electronics, and demanded by rapidly changing trends, have significant environmental implications (Berners-Lee, 2010; Collins, 2014; Gibson and Stanes, 2011; Hitchings et al., 2015). Concerns over the wide-reaching implications of excessive consumption contribute to young people's positioning as environmental offenders rather than heroes.

The environmental impacts of seemingly benign consumer items - such as a piece of clothing or electronics - need to be understood across a range of domains: production and manufacturing, distribution, use, waste/divestment and the social ethics of consumption (Gibson et al., 2013; Stanes, 2008). In addition to concerns about resource use and waste generation, calculation frameworks such as the carbon footprint have been vital in raising awareness of the climate change impacts of products (Berners-Lee, 2010). An example of this is Berners-Lee's (2010) discussion of direct and indirect carbon emissions for everyday items - from clothes to televisions. Direct carbon emissions are generated when an item is in use (for instance, the tailpipe emissions from a car, or the carbon emissions generated by the electricity needed to power a computer). Indirect emissions refer to the carbon emissions 
embedded within objects throughout their lifecycle. By the time a mobile phone makes its way to a consumer, for example, it already has a vast environmental legacy associated with resource extraction, manufacture and distribution (Gibson et al., 2013). Combined, the embedded indirect and direct carbon emissions of a mobile phone are estimated to be $47 \mathrm{~kg}$ $\mathrm{CO}_{2} \mathrm{e}$ per year (Berners-Lee, 2010). This figure includes manufacturing, transport before sale, the average power consumed by the mobile phone, energy required to transmit calls across a network and base station stations emissions (Berners-Lee, 2010). Once in use, patterns of everyday object care and maintenance - such as washing and drying clothing - also generate environmental impacts (Berners-Lee, 2010; Stanes, 2008). Berners-Lee (2010) estimated that a pair of cotton jeans, for instance, generates a minimum of $100 \mathrm{~g} \mathrm{CO}_{2} \mathrm{e}$ per day (when laundry is considered) for the typical British wearer.

As goods become unwanted, less useful or unfashionable, they make their way through stages of recycling or reuse to landfill; chemicals used in production are leeched, contaminating the environment. The inclusion of metals such as gold, palladium, silver, copper and platinum makes mobile phones the most valuable form of e-waste (Gibson et al., 2013). But low rates of recycling and inadequate and unsafe practices of dismantling mobile phones means that hazardous less valuable materials (like persistent bioaccumulative toxins PBTs) linger in the environment causing health and environmental damage (Gibson et al., 2013). Importantly, the environmental impacts of any consumer item - whether a piece of clothing, a mobile phone, a television or a tablet - is invariably escalated the quicker the item is discarded. Concerns around the generation of waste have caused the term 'throw-away society' to be associated with consumer cultures in the Global North. But the presumption of thoughtless and wasteful disposal has been challenged by geographers, including Gregson et al. (2007) and Collins (2014), who have argued that it is important to remember that the pathway to divestment is 
more than getting rid of an item. Divestment is equally about the movement of an item, the development of self-identity and a reflection of the relationship between people and things (Collins 2014). The environmental implications of everyday consumer items - and of the seemingly profligate consumption patterns of contemporary young people in the Global North - are far from inconsequential.

Young people's resource consumption is not limited to material possessions. A small number of studies have explored young people’s direct use of resources such as energy and water (Gram-Hanssen, 2007; Hitchings and Lee, 2008; Percy-Smith and Burns, 2013; Stanes et al., 2015). A common conclusion from these studies has been that young people in the Global North also consume these resources wastefully and excessively. In their Australian household sustainability survey, geographers Stanes et al. (2015) found that young people were far less willing than older generations to compromise on matters of cleanliness and hygiene. Generation Y householders reported laundering their clothing more frequently and spending more time in the shower, than older generations - both which have implications for water and energy use. These results mirror Gram-Hanssen’s (2007) study of showering and laundry practices among nine Danish teenagers, aged 13 to 15. The interviews with teens alongside their parents or guardians revealed that young people's expectations of cleanliness (and attendant water and energy consumption) were most often shaped by family norms, but also by peer group influence. The teens in Gram-Hanssen’s (2007) study were all heavily committed to a regular (and at times excessive) cleanliness routine that was inseparably connected to the avoidance of sweat and sweat odor - and which exceeded the norms practised by older generations. Showering and changing clothes at least once per day was unquestionable. The sustainability impacts of water and energy consumption associated with these cleanliness practices were ignored. The social and cultural influences that shape 
patterns of cleanliness will lead to greater energy and water consumption as these teens transition from childhood to adulthood (Gram-Hanssen, 2007). Elsewhere, Hitchings and Lee (2008) considered the intersection of air-conditioning use with social practice and sensual expectations among a group of eight twenty-something Singaporeans. Interviews revealed a uniform reliance of living with air-conditioning in tropical Singapore (Hitchings and Lee, 2008). While the placement of air-conditioning in both public and private spheres was thought of as a necessity to prevent the distaste of sweat and odor, cooler ambient environments also allowed this group of young people to present their identities through dress in a greater number of ways (Hitchings and Lee, 2008).

While the environmental implications of resource consumption patterns in the Global North are indeed profound and unsustainable, a range of recent studies have demonstrated that many young people do not identify with the hedonistic consumer tag (Autio, 2005; Hitchings et al., 2015; Wilska, 2003). 'Real' young people are, of course, far more diverse than this stereotype allows.

\section{Complicating the hedonistic consumer label}

Materialistic, object-driven identities are not always looked upon as a favorable expression of self - even amongst young people themselves (Autio et al., 2009; Wilska, 2003). In their Australian survey, Bentley et al. (2004) found that many young people were critical of the consumer culture that they are presumed to be located within. Almost 90 per cent of young people surveyed believed that 'young people buy too much stuff' (Bentley et al., 2004). Focusing on their own individual consumption habits, 92 per cent of young people believed that 'by changing my behavior I could bring about positive change' to the environment, but also the well-being of others (Bentley et al., 2004). Further, 95 per cent of young people 
surveyed agreed or strongly agreed that they were 'personally responsible for making my consumption more sustainable'. Focusing on mobile phone consumption patterns via a survey of 637 Finnish young people, Wilska (2003) found that many teenagers were keen to present themselves as being 'less materialistic' than their peers. While young people connected mobile phone consumption to 'trends', the need to obtain 'cool' styles was infrequently acted upon. The majority of the young respondents were actually 'thrifty' mobile phone consumers, a trait which was associated with environmental consciousness and careful consumption patterns more generally. Even some of the most ‘hedonistic’ participants in Autio’s (2005) Finnish study of youth consumer culture expressed emotions of shame after reflecting on their own self-confessed 'wastrel' identities. Contra the 'thoughtless' consumer tag, teenage participants (aged between 16 and 19) expressed concern about wasteful and unnecessary consumption and spending. In a 'play between hedonism and self-control' these young study participants did not always deem consumption to be necessary or desirable (Autio, 2005:340).

Geographers, Collins and Hitchings (2012; see also Collins, 2014, 2015 and Hitchings et al., 2015) have also sought to complicate the hedonistic and wasteful consumer caricature. Their important work has argued that scholars of contemporary youth consumption have paid insufficient attention to the ways that young people value, use and eventually dispose of items. There is evidence of environmental awareness - and 'green' behaviors - embedded within young people’s unique consumption patterns (Hitchings et al., 2015). As noted throughout this chapter, contemporary young people in the Global North have been criticized for their apparently short-lived satisfaction with products, and for the instability of their wants and desires (Griffin et al., 2005; Hume, 2010). Their consumption patterns have often been deemed problematic by comparison with the practices of preceding generations particularly their 'frugal' grandparents who grew up in times of hardship such as war or 
recession (Stanes et al., 2015). Yet many of the young participants in Collins’ (2014) study displayed an ethic of care towards material objects - such as clothes, electronics or toys even as they disposed of them. Using detailed research methods including interviews and photo-elicitation involving 26 teens (aged 16 to 19) in secondary schools across East Anglia (UK), Collins (2014) observed strategies for avoiding waste. The young study participants put considerable effort into retaining items, even if they no longer used or wanted them - just in case they needed a 'back up'. Holding onto items was legitimized with recourse to potential future utility of an item; a spare mobile phone, for example, held in a drawer in case the one in use broke down (Collins, 2014). While rates of competence and ability to mend or repair items were relatively low, the majority of the 26 young participants indicated that they would first attempt to repair a possession (usually clothing or gadgets) either themselves, or with assistance from family members or professionals before disposing of an item. Within Collins’ (2014) study, a small group of five participants identified as active menders or reusers capable of extending the life of particular objects or returning them to active use. Collins (2014) highlighted the sense of competence and efficacy that this group of young menders and repairers experienced as a way of encouraging a more thoughtful relationship to ‘things’ (see also Percy-Smith and Burns, 2013). While behaviors of care or repair for unwanted objects did not appear to be motivated by environmental concern, Collins (2014) argued that there is potential for such attitudes towards used objects to be built in to discussions around more sustainable consumption (see also Hitchings et al., 2015).

Geographers have also researched the ways in which young people have sought out alternatives to limit their consumption. Stanes (2008) found evidence of careful purchaseminimization strategies in the clothing practices of young people in Wollongong, Australia. The established relationships of contemporary youth peer networks enabled cultures of 
clothes sharing, swapping and lending, particularly amongst groups of young women (Stanes, 2008). These acts reduced the amount of clothing that was being bought and consumed, while at the same time expanding the young women's wardrobes. Elsewhere, Dowling and Simpson (2013) highlighted several signals that point towards a changing car identity among this generation of young people in Australia. Computers and mobile phones have assumed a prime position as status symbols in recent years, and as evidenced by declining car sales and a reduction in the number of young people getting their drivers licenses, many young Australians are finding alternative ways of getting around. In particular, an increase in the number of young people using car sharing initiatives has also signaled a shift towards a 'postprivate-car society’ (Dowling and Simpson 2013:431).

Such studies point towards the existence of unique - and at times inadvertent - cultures of sustainability amongst contemporary young people. Today’s young consumers, it seems, are not devoid of environmental and moral concerns about their consumption patterns. However, their everyday sustainabilities may remain hidden if traditional expectations of what environmentalism 'looks like' continue to be prioritized. There is growing evidence that young people consciously and unconsciously practise environmentalism in unique ways distinct from those of older generations (Hersch and Viscusi, 2006; Hitchings et al., 2015; Stanes et al., 2015). For the most part, the aforementioned studies have found that these more sustainable consumption patterns (which were often inadvertent) were not perceived by young people as ‘a limitation to’ enjoying the processes and experiences of consumption (Autio et al., 2009: 45). Rather than mourning the disappearance of 'old-fashioned' values such as thrift and frugality - and thereby pitting young people against older generations in unhelpful ways - research attention should be devoted towards better understanding how contemporary young people are enacting similar values in 'modern' and innovative ways 
(Percy-Smith and Burns, 2013). For instance, Vivoni (2013) identified how skateboarding cultures amongst young people in Chicago fostered an ethic of care for local environments. Skateboarding projects targeted at young people promoted alternative sustainabilties within urban spaces - including, for instance, recycled art installations, reuse of materials for ramps and street obstacles, and environmental justice initiatives. In this example, urban spaces were transformed into 'hands-on learning centers' that promoted environmental awareness (Vivoni 2013: 346). These studies suggest that entanglements of youth and environmental sustainability do not always involve obvious actions (like planting trees or recycling plastic bottles); and can instead emerge (at times inadvertently) out of relationships with others and the physicality of taken-for-granted environments and spaces. Contemporary young people often practice an 'alternative ethic of care' (Vivoni, 2013: 340) that are poorly accounted for by existing measures. Geographers ought to look beyond sites of acquisition (such as the shopping mall) to develop a deeper sense of young people’s ways of valuing material objects - contra the prevailing rhetoric of thoughtless waste (Collins and Hitchings, 2012:197).

However, even those young people who express high levels of commitment to environmental issues still experience moments where the responsibilities of environmental citizenship are undermined by the temptations of modern consumption and comforts (Collins and Hitchings, 2012). The desire to consume can often outweigh environmental commitment (Autio and Heinonen, 2004; Breunig et al., 2013). For instance, in Breunig et al.'s (2013) Canadian study of secondary school students 75 per cent reported feeling inconvenienced by the prospect of acting upon pro-environmental intentions. Fundamental changes in everyday behaviors, such as carpooling to and from school, lost out to ideas of inconvenience and ensuing lack of freedom (Breunig et al. 2013). Instead, students were more likely to be engaged in everyday sustainabilities through what the authors called 'domestic environmental behaviors' (Breunig 
et al. 2013: 380), or small scale actions like recycling or turning the lights off in rooms that were not being used.

\section{Conclusion}

This chapter has considered the apparent disjuncture between the popular perceptions of contemporary young people as wasteful and hedonistic consumers and their alternative positioning as environmental heroes. This binary has effectively split debates around youth, the environment and sustainability into 'the good' and 'the bad'. But these descriptions are too simplistic and partial. This chapter has argued that contemporary young people in the Global North do not fit neatly into either of these categories. One-dimensional conceptualizations of young people do not match lived, everyday complexities of their lifestyles. The life stage of youth is often unpredictable. Young people's identities are multiple, intersecting and fluid (Hopkins, 2013) - with implications for their environmental values and practices.

Recent geographical scholarship has made strong efforts to develop a more nuanced picture of contemporary young people (Collins, 2014, 2015; Collins and Hitchings 2012; Gibson and Stanes, 2011; Hadfield-Hill, 2013; Hitchings et al., 2015; Hopkins, 2013; Horton et al. 2013; Percy-Smith and Burns, 2013; Stanes et al., 2015; Vivoni, 2013). But there is still some way to go. Many young people are concerned about environmental issues in general, and climate change in particular (Autio et al., 2009; Bentley et al., 2004; CarbonTrust 2012; Fielding and Head 2012; Forum for the Future 2008; Jenkins and Pell 2006; Stanes et al., 2015). They have the capacity to influence change in response to pressing environmental problems across a range of geographical scales and have been targeted by NGOs and schools in recent years to nurture the role they can play as change-makers in response to pressing environmental and 
social problems across multiple scales. But young people should not be seen as a uniform mass. Their capacities need to be viewed in the present tense, rather than being framed around future potentialities (Evans and Honeyford, 2012; Hayward, 2012). Further, contemporary young people's environmental capacities need to be understood on their own terms - they are unique, distinct from the sustainabilities of previous generations. Many young people have already been practising an 'alternative ethic of care' (Vivoni, 2013:340) for the environment that has been poorly accounted for by existing measures. Future research attention ought to be devoted towards identifying, heralding and promoting practices that are prevalent among contemporary young people, which may have (inadvertently) positive impacts on environmental objectives (Hitchings et al., 2015). At the same time, it is important to avoid romanticizing this potential. No one generational cohort is going to solve environmental issues facing modern society. Communities across all geographical scales will also need to work together in order to face uncertain environmental futures. The environmental hero label is also unhelpful because it suggests that contemporary young people can single-handedly right the wrongs of previous generations. Instead, the evidence presented throughout this chapter points towards the benefits of mutual, inter-generational learning (Ballayntine et al. 2001; Collins, 2015; Klocker et al. 2012; Stanes et al., 2015). The sustainabilities of all generations will need to be harnessed in order to respond to a range of complex and pressing environmental challenges. 


\section{References}

Abrams, M. (1959). The Teenage Consumer. London: London Press Exchange.

Autio, M. (2005). The morality of spending in Finnish youth consumer culture. International Journal of Consumer Studies. 29(4), 332-341. DOI: 10.1111/j.1470-6431.2005.00442.x.

Autio, M., \& Heinonen, V. (2004). To consume or not to consume? Young people's environmentalism in the affluent Finnish society. Young. 12(2), 137-153. DOI:

$10.1177 / 1103308804042104$.

Autio, M., Heiskanen, E., \& Heinonen, V. (2009). Narratives of 'green' consumers: the antihero, the environmental hero and the anarchist. Journal of Consumer Behavior. 8, 40-53. DOI: $10.1002 / c b .272$.

Ballantyne, R., Fien, J., \& Packer, J. (2001). Program effectiveness in facilitating intergenerational influence in environmental education: lessons from the field. The Journal of Environmental Education. 32(4), 8-15. DOI:10.1080/00958960109598657.

Bentley, M., Fien, J., \& Neil, C. (2004). Sustainable Consumption: Young Australians as Agents of Change. Canberra: Australian Government Department of Family and Community Services.

Berners-Lee, M. (2010). How Bad are Bananas? The Carbon Footprint of Nearly Everything. London: Profile Books.

Blake, J. (1999). Overcoming the 'value-action gap' in environmental policy: Tensions between national policy and local experience. Local Environment: The International Journal of Justice and Sustainability. 4(3), 257-278. DOI:10.1080/13549839908725599.

Breunig, M., Murtell, J., Russell, C., \& Howard, R. (2013). The impact of integrated environmental studies programs: are students motivated to act pro-environmentally? Environmental Education Research. 20(3), 372-386. DOI: 10.1080/13504622.2013.807326.

Büttner, T., \& Grübler, A. (1995). The birth of a 'Green' generation? Generational dynamics of resource consumption patterns. Technological Forecasting and Social Change. 50, 113134. DOI:10.1016/0040-1625(95)00052-C.

Carbon Trust (2012). A global survey of young adults' perceptions of carbon and climate change. Carbon Trust, London.

http://www.carbontrust.com/media/56157/carbon_trust_survey_young_adults_perceptions_ca rbon_and_climate_change.pdf. Accessed 17 June 2013.

Collins, R.C. (2015). Keeping it in the family? Re-focusing household sustainability. Geoforum. 60, 22-32.

Collins, R.C. (2014). Excessive... but not wasteful? Exploring young people's material consumption through the lens of divestment. London, United Kingdom: University College London.

Collins, R., \& Hitchings, R. (2012). A tale of two teens: disciplinary boundaries and geographical opportunities in youth consumption and sustainability research. Area. 44(2), 193-199. DOI: 10.1111/j.1475-4762.2011.01075.x. 
Dowling, R. \& Simpson, C. (2013). 'Shift - the way you move': reconstituting automobility. Continuum: Journal of Media \& Cultural Studies. 27 (3), 421-

433.DOI:10.1080/10304312.2013.772111.

Evans, B. \& Honeyford, E.J. (2012). Brighter futures, greener lives': children and young people in UK sustainable development policy. In P. Kraftl, P. Horton, F. Tucker (Eds.) Critical Geographies of Childhood and Youth, (pp 61-77). Bristol, Policy Press.

Fielding, K., \& Head, B. (2012). Determinants of young Australians' environmental actions: the role of responsibility attributions, locus of control, knowledge and attitudes. Environmental Education Research. 18(2), 171-186. DOI: 10.1080/13504622.2011.592936.

Forum For The Future (2008). Future Leaders Survey 2007-8. London: Forum For The Future/UCAS.https://www.forumforthefuture.org/sites/default/files/project/downloads/futurel eaders0708.pdf Accessed 26 September 2014.

Gram-Hanssen, K. (2007). Teenage consumption of cleanliness: how to make it sustainable. Sustainability: Science, Practice and Policy. 3(2), 15-23.

Gregson, N., Metcalfe, A. \& Crewe, L. (2007). Identity, mobility and the throwaway society. Environment and planning D : society and space. 25 (4), 682-700. DOI:10.1068/d418t.

Gibson, C., Farbotko, C., Gill, N., Head, L. \& Waitt, G. (2013). Household Sustainability: Challenges and Dilemmas in Everyday Life. Cheltenham: Edward Elgar.

Gibson, C. \& Stanes, E. (2011). Is green the new black? Exploring ethical fashion consumption. In T. Lewis \& E. Potter (Eds.), Ethical Consumption: A Critical Introduction (pp. 169-185). Abingdon: Routledge.

Griffin, C., Phoenix, A., Croghan, R., \& Hunter, J. (2005). Consuming identities: young people, cultural forms and negotiations in households., ESRC End of Award Research Report (R000239287 \& R000239287-A).http://people.bath.ac.uk/psscg/eoareportythcons.WP.htm. Accessed 19 August 2013.

Hadfill-Hill, S. (2013). Living in a sustainable community: new spaces, new behaviors? Local Environment: The International Journal of Justice and Sustainability. 18(3), 354-371. DOI: 10.1080/13549839.2012.714760.

Han, E. (2015, March 15) Consumer tribes - how Gen Y, X, baby boomers shop and respond to brand marketing, Sydney Morning Herald. www.smh.com.au/national/consumer-tribes-how-gen-y-x-baby-boomers-shop-and-respondto-brand-marketing-20150314-141tgp.html. Accessed 16 March 2015.

Hayward, B. (2012). Children, citizenship and environment. London: Routledge.

Heiss, J.\& Marras, I. (2009). Educating and engaging youth in sustainable consumption: YouthXchange programme. In P. Corcoran \& P. Osano (Eds.), Young people, Education and Sustainable Development: Exploring principles, perspectives and praxis (pp181-190). The Netherlands: Wageningen Academic Publishers. 
Hersch, J. \& Viscusi, W.K. (2006). The generational divide in support for environmental policies: European evidence. Climatic Change. 77(1-2), 121-236.

Hitchings, R., Collins, R. \& Day, R. (2015). Inadvertent environmentalism and the actionvalue opportunity: reflections from studies at both ends of the generational spectrum. Local Environment: The International Journal of Justice and Sustainability. 20 (3), 369-385. DOI:10.1080/13549839.2013.852524.

Hitchings, R. \& Lee, S, J. (2008). Air conditioning and the material culture of routine human encasement. The Journal of Material Culture. 13, 251-265. DOI: $10.1177 / 1359183508095495$.

Hoey, T. (2008, March 16). How to turn Generation Y in to Generation \$. Sydney Morning Herald. http://www.smh.com.au/news/money/how-to-turn-generation-y-into-generation/2008/03/15/1205472147099.html. Accessed 15 July 2011.

Hopkins, P. (2013). Young People, Place and Identity. Abingdon: Routledge.

Hopkins, P. and Pain, R. (2007). Geographies of age: thinking relationally. Area. 39(3), 287294.

Horton, J., Hadfield-Hill, S., Christensen, P., \& Kraftl, P. (2013). Children, young people and sustainability: introduction to special issue, Local Environment: The International Journal of Justice and Sustainability, 1 (3), 249-254. DOI: 10.1080/13549839.2012.760766.

Howe, N., \& Strauss, W. (2000). Millennials Rising. New York: Vintage Books

Hume, M. (2010). Compassion without action: Examining the young consumers consumption and attitude to sustainable consumption. Journal of World Business. 45, 385-394.

DOI:10.1016/j.jwb.2009.08.007.

James A \& James A. (2004). Construction Childhood: Theory, Policy and Social Practice. Basingstoke: Palgrave Macmillan.

Jenkins, E.W., \& Pell, R. J. (2006). 'Me and the Environmental Challenges”: A survey of English secondary school students' attitudes towards the environment. International Journal of Science Education. 28(7), 765-780. DOI: 10.1080/09500690500498336.

Klocker, N., Gibson, C. \& Borger, E. (2012). Living together but apart: Material geographies of everyday sustainability in extended family households. Environment and Planning A. 44, 2240-2259. DOI:10.1068/a44594.

Kollmuss, A. \& Agyeman, J. (2002). Mind the Gap: Why do people act environmentally and what are the barriers to pro-environmental behaviour? Environmental Education Research. 8(3), 239-260. DOI: 10.1080/1350462022014540 1.

Larsson, B., Andersson, M., \& Osbeck, C. (2010). Bringing environmentalism home: Children's influence on family consumption in the Nordic countries and beyond.

Childhood. 17 (1), 129-147. DOI: 10.1177/0907568209351554. 
Malone, K. (2001). Children, Youth and Sustainable Cities. Local Environment: The International Journal of Justice and Sustainability. 6(1) 5-12. DOI:

10.1080/13549830120024215.

Ojala, M. (2007). Confronting macro-social worries: worry about environmental problems and proactive coping among a group of young volunteers. Futures. 39, 729-745.

DOI:10.1016/j.futures.2006.11.007.

Ojala, M. (2012). Hope and climate change: the importance of hope for environmental engagement among young people. Environmental Education Research. 18(5),

625-642. DOI:10.1080/13504622.2011.637157.

Percy-Smith, B. (2010). Councils, consultation and community: rethinking the spaces for children and young people's participation. Children's Geographies. 8(2), 107-122. DOI: 10.1080/14733281003691368.

Percy-Smith, B. \& Burns, D. (2013). Exploring the role of children and young people as agents of change in sustainable development. Local Environment: The International Journal of Justice and Sustainability. 18(3), 323-339.DOI:

10.1080/13549839.2012.729565

Stanes, E. (2008). Is Green the New Black? Questions of Consumption and Sustainability for the Fashion Industry. (Unpublished honours thesis). University of Wollongong, Australia.

Stanes, E., Klocker, N. \& Gibson, C. (2015). Young adult households and domestic sustainabilities. Geoforum. 65, 46-58. DOI:

http://dx.doi.org/10.1016/j.geoforum.2015.07.007

UNEP/UNESCO (2006) Report of the UNEP/UNESCO YouthXchange Networking workshop held in Paris, April 2006. Unpublished.

United Nations Conference on Environment and Development. (1992). Agenda 21, Rio Declaration, Forest Principles. New York: United Nations. Accessed 9 September 2014.

United Nations Environmental Programme (no date). Retrieved from http://www.unep.org/

Valentine, G. (2000). Exploring children and young peoples narratives of identity. Geoforum, 31(2), 257-267. DOI:10.1016/S0016-7185(99)00047-0.

Valentine, G. (2003). Boundary crossings: transition from childhood to adulthood. Children's Geographies. 1(1), 37-52.

Veblen, T. (2009 [1899]). The Theory of the Leisure Class. London and New York: Macmillan.

Vivoni, F. (2013). Waxing ledges: built environments, alternative sustainability, and the Chicago skateboarding scene. Local Environment: The International Journal of Justice and Sustainability. 18(3), 340-353. DOI: 10.1080/13549839.2012.714761.

Wilska, T, A. (2003). Mobile phone use as part of young people's consumption styles. Journal of Consumer Policy. 26, 441-463. 
